\title{
Correction to: Radiofrequency ablation combined with transarterial chemoembolization in treatment of hepatocellular carcinoma adjacent to the second hepatic hilus
}

\author{
Meng-Li Chen ${ }^{1} \cdot$ Hai-Liang $\mathrm{Li}^{1}$. Chen-Yang Guo ${ }^{1} \cdot$ Hao Zhang ${ }^{1} \cdot$ Hang Yuan ${ }^{1} \cdot{\text { Zhen } \mathrm{Li}^{2}}^{2}$ Jung-Hoon Park ${ }^{3}$. \\ Hong-Tao $\mathrm{Hu}^{1}$ (D)
}

Published online: 7 February 2022

(c) Springer Science+Business Media, LLC, part of Springer Nature 2022

Correction to: Abdominal Radiology

https://doi.org/10.1007/s00261-021-03304-4

The original version of this article has an error in the affiliation of all the authors. The authors affiliations are corrected.

Publisher's Note Springer Nature remains neutral with regard to jurisdictional claims in published maps and institutional affiliations.

The original article can be found online at https://doi.org/10.1007/ s00261-021-03304-4.

Hong-Tao $\mathrm{Hu}$

huhongtaogy@163.com

1 Minimally Invasive and Interventional Department, Affiliated Cancer Hospital of Zhengzhou University, Henan Cancer Hospital, 127 Dongming Road, Zhengzhou 450008, Henan, China

2 Department of Interventional Radiology, First Affiliated Hospital of Zhengzhou University, Zhengzhou 450052, Henan, China

3 Biomedical Engineering Research Center, Asan Institute for Life Sciences, Asan Medical Center, 88 Olympic-ro 43-gil, Songpa-gu, Seoul 05505, Republic of Korea 